\title{
Emerging Roles of Lead Buyer Governance for Sustainability Across Global Production Networks
}

\author{
Rachel Alexander ${ }^{1}$
}

Received: 3 October 2017 / Accepted: 23 May 2019 / Published online: 8 June 2019

(c) The Author(s) 2019

\begin{abstract}
Global production networks (GPNs) connect multiple producers involved in fragmented manufacturing processes. Major brands and retailers, considered as lead firms, are under increasing pressure to ensure products made through GPNs are produced sustainably. Theories of governance developed to understand dynamics in outsourced production can provide insight into this issue. However, these theories and related empirical research have often focused on relationships between lead firms and upper-tier suppliers. When manufacturing involves multiple fragmented stages, understanding the role of lead firms becomes more difficult. This article considers new governance roles that lead firms, as buyers, are playing when attempting to promote sustainable practices across all stages of production for buyer-driven industries. The focus is exploring the nature of new governance approaches which lead firms have developed in order to address diverse sustainability challenges found within GPNs, particularly related to lower-tier suppliers. These approaches can involve lead firms working through vertical buyer-seller links or developing new horizontal relationships, which link lead firms with lower-tier suppliers and governance processes in these suppliers' local productive systems. The findings draw from field research examining how top UK garment retailers provide governance to producers involved in creating cotton garments in India and a review of publicised policies and practices of these retailers related to promoting sustainable production. Five types of governance mechanisms that can involve vertical or horizontal links are identified. Considering the growth of new governance relationships expands previous conceptions of the roles of lead firm governance.
\end{abstract}

Keywords Global production networks · Governance $\cdot$ Sustainable production

\section{Introduction}

Contemporary manufacturing processes can involve lead firms identified with final products created through activities carried out by a network of suppliers each responsible for a different stage of production. With an understanding of sustainability challenges being created by processes which have harmful social or environmental impacts, behaviours of producers involved in any stage of production may contribute to perpetuating such challenges. Developing a better understanding of the governance involved in shaping practices used in fragmented global production networks (GPNs) connected to widespread sustainability challenges is a pressing global concern.

Rachel Alexander

r.alexander@1se.ac.uk

1 London School of Economics, London, England, UK
As many products are made through what have been considered as lead firm-driven processes (Gereffi 1994), an important consideration is the role that lead buyers play. While fragmentation provides commercial benefits for lead firms, it also involves a loss of direct control over production practices. Without direct control, lead firms, which are under increasing pressure to be responsible for sustainability challenges at all stages of production (Schrempf-Stirling et al. 2013), must develop strategies for influencing businesses producing their products. Davis et al. (2013) refer to the fact that increasing loss of control is taking place alongside an increase in the expectations for corporate social responsibility (CSR) as a 'responsibility paradox' and note that multinational firms are spreading their efforts to create positive social impact over a wider set of issues and locations. In this context, this article questions the roles that lead firms play in governance for sustainable production across fragmented production processes. 
Two gaps in literature on private governance for sustainable production are addressed. The first gap is that most research has focused on the relationship between lead firms and first-tier suppliers (Alexander 2018; Sauer and Seuring 2018). Notably, relationships between lead firms and lowertier suppliers are under-researched (for key exceptions see Mena et al. 2013; Nadvi and Raj-Reichert 2015; Kim and Davis 2016). Important considerations when exploring challenges related to sustainability that extend to raw material production are that often a large set of globally fragmented suppliers are involved and lead firms may not have any direct connections to lower-tier suppliers.

The second gap considered is that previous research on processes of lead firm governance has focused on lead firms as standard setters (Locke 2013; Lund-Thomsen and Lindgreen 2014). Lund-Thomsen and Lindgreen (2014) identify an evolution in the methods employed by lead firms seeking to control suppliers related to CSR issues. They outline the existence of a dominant compliance paradigm and the development of a cooperation paradigm which involves lead firms collaborating with their suppliers related to CSR issues. However, more research is needed to better understand the variety of mechanisms that lead firms use to govern suppliers' behaviour.

To explore these topics, this paper considers production as taking place within a GPN that includes all actors relevant to supporting production processes, such as support service providers and government agencies (Henderson et al. 2002; Coe and Yeung 2015). The GPN framework explicitly emphasises that all actors have embedded network, territorial and societal locations that shape their behaviour (Hess 2004). Within this network, the set of businesses involved in the creation of a product is considered as an extended supplier network (ESN) (Alexander 2018). The ESN's structure is formed by the diverse and intersecting vertical pathways created by buyer-seller links involving producers of component parts and intermediary inputs. The analysis in this paper focuses on how lead firms sitting at the top of ESNs seek to influence producers' practices. A case study network is explored that involves UK retailers sourcing cotton garments from Indian producers. Within this network, approaches that retailers are using to address challenges with sustainable production are classified and analysed.

In the context of sitting at the top of a complicated set of vertical pathways with limited scope to transmit vertical governance pressures, this article argues that lead firms play multiple governance roles. Within conventional commercial relationships, lead firms have limited connections to lower-tier producers. However, lead firms are overcoming this challenge by developing new governance approaches. Lead firms were found to use both vertical and horizontal governance paths in efforts to address sustainability challenges (Alexander 2018). Vertical pathways involve lead firms seeking to control suppliers through buyer-seller links. This can be limited to lead firms' relationships to first-tier suppliers or involve pressures that are expected to filter down through vertical links to lower-tier suppliers. Horizontal pathways involve lead firms creating governance relationships outside of vertical commercial connections. Horizontal connections can be developed through creating new interfirm relationships or creating relationships with other governance actors playing roles in the territorial locations where production takes place, such as NGOs or multi-stakeholder initiatives (MSIs).

With their use observed across both types of pathways, five mechanisms for lead firm governance for sustainability are identified. These mechanisms are defined as Hierarchical, Compliance, Support Services, Partnership and Promotion of Voluntary Change. All five mechanisms may be used simultaneously by a single lead firm. The ability to use each approach is shaped by the relationship lead firms have with producers and the nature of the sustainability challenges being faced.

This study uses a GPN approach to understand challenges lead firms face with CSR in their supplier networks. Specifically, it provides a deeper understanding of the governance roles lead firms play across fragmented networks of suppliers drawing in under-researched connections with lower-tier suppliers. The diversity of roles played by lead firms within this case study provides a new understanding of the process of buyer-driven governance. Lead firms are found to play multiple simultaneous governance roles. Overall, buyer-led governance across the case study was found to be a limited process, with few connections found between lead firms and lower-tier suppliers. However, the role of UK garment retailers in governance for sustainable production is expanding.

The focus of this paper differs from much research on sustainable supply chain managment (SSCM) that focuses on success from a lead firm perspective, which can be measured by decreasing their risk (Sauer and Seuring 2018). Instead, this paper emphasises how pressures are experienced in local productive systems experiencing sustainability challenges. The analysis provided on the two governance pathways and five governance mechanisms can help practitioners develop better interventions that may be able to create longer-term embedded changes within local production systems.

The rest of the article is structured as follows. The second section reviews relevant research seeking to understand dynamics of fragmented production systems, processes of buyer-driven governance and lead firms' efforts to promote sustainable production practices. The third section discusses the methodology. The fourth section presents the empirical results found within the case study. 
The fifth section discusses the results. The sixth section provides a conclusion.

\section{Buyer-Driven Governance for Fragmented Production}

Sustainable systems have been seen to rely on an interdependence of practices related to social, economic and environmental issues (Carter and Rogers 2008; Sumner 2005). Challenges with achieving the objective of sustainable production are connected to all three issues. This objective has been explored through socioeconomic research in geography and sociology which has looked at production taking place in systems known as global commodity chains (GCCs), global value chains (GVCs) and GPNs and through business-focused research in the field of supply chain management (SCM). This study builds on these socioeconomic frameworks and draws insight from SSCM research.

GCC, GVC and GPN literature seeks to understand global economic systems. Studies using these concepts have often focused on lead firms located in Western countries relying on businesses in low-wage countries. Issues considered have included how profits are distributed between businesses connected in multiple stages of producing one product, local implications of businesses connecting to global networks and the evolution of global standards (Gereffi and Lee 2012; Bair and Werner 2015). Much of this research has focused on exploring the governance roles played by lead firms.

SCM literature has focused on the relationships between firms and first-tier suppliers. However, recent research, particularly studies looking at SSCM, has started to explore connections between lead firms and lower-tier suppliers (e.g. Mena et al. 2013; Tachizawa and Wong 2014; Sauer and Seuring 2018). Research from this field has used multiple organisational theories to investigate dynamics involved in the connections between lead firms and their suppliers (Sarkis et al. 2011).

The first part of this section reviews frameworks used to conceptualise fragmented production processes. The second part discusses theories of governance that have been used to understand relationships in fragmented production. The third part considers perspectives from SSCM literature than can help to explore interfirm relationships. The fourth part presents key insights from the emerging literature which explicitly focuses on understanding dynamics that connect multiple tiers of suppliers.

\section{Conceptualising Fragmented Production Systems}

Three major frameworks have been used to explore globally fragmented production from a socio-economic perspective. The GVC perspective, developed in the 1990s, evolved from the GCC approach. By looking at the organisational field that developed in post-World War II production systems, the GCC approach provided a way to understand the importance of businesses as actors shaping people's lives globally (Bair 2008). Gereffi (1994) proposed that lead firms, which are the most profitable firms in an industry, govern GCCs by controlling access to major resources such as product design, new technologies, brand names or consumer demand.

The GVC framework focuses more specifically on interfirm relationships. GVCs have been defined as incorporating "the full range of activities that are required to bring a product from its conception, through the different phases of production to end use and beyond (Pietrobelli and Saliola 2008, p. 950)". This approach has often been used to understand power differentials between lead firms and businesses that are seen to be dependent on lead firms (Gereffi et al. 2005; Humphrey and Schmitz 2001).

The GPN framework, developed based on a geographical perspective, has been defined as, "an organisational arrangement, comprising interconnected economic and non-economic actors, coordinated by a global lead firm and producing goods or services across multiple geographical locations for worldwide markets (Coe and Yeung 2015, pp. 1-2)". This framework seeks to cover all relevant sets of actors and relationships (Coe et al. 2008). While definitions of the GCC and GVC frameworks have incorporated non-firm actors and territoriality, research framed under these approaches has often focused on interfirm relationships (Coe and Yeung 2015). Compared to these frameworks, the GPN approach more strongly emphasises considering factors outside direct buyer-seller relationships, with GPNs having been considered to be economic, political, social and cultural phenomena (Levy 2008; Coe et al. 2008). The GPN framework involves three conceptual categories and four conceptual dimensions (Henderson et al. 2002; Coe and Yeung 2015). The conceptual categories include value (creation, enhancement, capture), power (corporate, collective and institutional) and embeddedness (territorial, network and societal). The conceptual dimensions include firms (ownership, "architecture"), sectors (technologies and products/markets), networks ("architecture", power configuration and governance) and institutions (governmental, quasi-governmental, non-governmental). Governance pressures in GPNs are seen not merely as functioning through top down processes but involving "dynamically inter-connected and simultaneous processes 
(p. 273)" with asymmetrical power relationships (Coe et al. 2008). An important understanding coming out of the GPN approach is the evolutionary nature of networks. Network structures are seen to be shaped by processes of path dependency and dynamic competitive drivers (Henderson et al. 2002; Coe and Yeung 2015).

Alternate models exist which also look at supply chains as networks. One such theory is social network theory, which focuses on the structure of a network as determining the behaviour of its members (Borgatti and Li 2009). The GPN conception of network differs from social network theory in that it looks at individual actors as having agency and making decisions based on multiple socioeconomic factors.

Another way of viewing supplier networks is to conceptualise them as complex adaptive systems (CASs) (Choi et al. 2001). This approach draws from systems theory, which considers components of a system to be best understood within the system rather than alone and from complexity theory, which involves considering that reactions in complex systems are difficult to predict (Tachizawa and Wong 2014). These systems are seen as being made up of agents whose individual decisions interact within the overall system through processes that can lead to the emergence of new structures, patterns and properties that were not pre-planned by any one agent.

The broad field of SCM explores relationships between lead firms and suppliers. Approaches used have involved agency theory, balance theory, complexity theory, ecological modernisation theory, information theory, institutional theory, network focused perspectives, path dependency, relational view, resource based view, resource dependence theory, social embeddedness, stakeholder theory, systems theory and transaction cost economics (Sarkis et al. 2011; Tachizawa and Wong 2014). One key difference between SCM literature and GPN literature is the latter looks at societal relationships with businesses seen as one of many actors in a system, whereas the former tends to focus on firms as the key actor and the outside world as something that the firm interacts with. Another key difference is that SCM literature has played limited attention to local context (Sauer and Seuring 2018).

While the multiple frameworks described above can be used for answering questions about fragmented production, this study uses a GPN approach because it provides a way to explore behaviour of all actors involved in shaping production processes and considers non-linear dynamics along with the importance of embeddedness. In proposing the GPN framework, Henderson et al. (2002) explicitly say that looking at firms is beneficial for exploring possibilities of economic development. This study contributes to research which has expanded this potential by using the framework to also incorporate social and environmental issues.

\section{Lead Firm Governance over Fragmented Production}

Several theories have been developed to explain processes through which lead firms govern producers. A key insight was the classification of production processes as buyer or producer driven (Gereffi 1994). Buyer-driven industries generally have brands and retailers as lead firms and producerdriven industries have manufacturers as lead firms. This article focuses on dynamics that can be found in buyer-driven industries.

Buyer-driven governance was identified as taking place in industries which relied on a dispersed set of producers as suppliers. This outsourcing provides some advantages, such as increased flexibility; however, it also results in a loss of ability to directly control the practices used during production processes. In buyer-driven industries, lead firms maintain control of high-value activities such as branding and marketing. It has been argued that all industries are moving towards a buyer-driven model (Gibbon et al. 2008).

Focusing on lead firms' abilities to control first-tier suppliers, Gereffi et al. (2005) developed a framework that identified five forms of buyer governance. In this framework, the role played by buyers is determined by the complexity of transactions, codifiability of information and capability of suppliers. Various combinations of these factors are seen as resulting in five types of network governance processes: markets, modular value chains, relational value chains, captive value chains and hierarchy. Market connections involve price-based transactions and have low costs of switching between suppliers. Modular connections involve suppliers creating products based on a buyer's design specifications. Relational connections feature mutual dependence and are likely to involve family or ethnic ties, benefit from spatial proximity or rely on trust and reputation with long-term relationships. Captive connections generally involve small suppliers highly dependent on larger buyers that employ a high degree of monitoring and control. Hierarchy involves complete vertical integration.

Moving beyond earlier governance conceptions focused on exploring dynamics related to competition, researchers have begun to explore topics related to lead buyers' roles in governance for sustainability. Some types of lead firms in some sectors have faced pressures to promote sustainability for outsourced production (Brown and Knudsen 2015). Facing such pressure, many garment brands and retailers developed CSR policies in the 1990s, which often involved developing codes of conduct for their suppliers (Bartley 2003; O'Rourke 2003). These compliance-based initiatives have since become widespread with sourcing policies generally 
focused on first-tier suppliers (O'Rourke 2003; Welford and Frost 2006). In exploring how lead firms seek to govern their first-tier suppliers related to sustainability challenges, LundThomsen and Lindgreen (2014) distinguished between two paradigms as the dominant compliance paradigm and the emerging cooperative paradigm. The cooperative paradigm is seen to involve buyers questioning their own role in driving sustainability challenges, sharing in the responsibility for addressing challenges and reforming auditing systems to get a better understanding of production practices.

\section{Interfirm Dynamics in SSCM Literature}

SSCM literature has employed multiple theories to understand relationships and dynamics between actors in fragmented production. SCM studies have mainly looked at dyadic relationships but some have looked at triads involving either one buyer and two first-tier suppliers or a buyer, a first-tier and a second-tier supplier (Tachizawa and Wong 2014). However, more recent research, which is considered below, has begun to apply these theories to look at multi-tier relationships.

One theory that has been used to look at buyer-seller relationships in both the GVC approach and in SCM literature is transaction cost economics (Williamson 1979, 1981). Building on the make versus buy logic developed by Coase (1937), this theory postulates that firms make decisions about whether to keep activities vertically integrated or to outsource them through considering costs based on uncertainty, frequency and the investments required. Asset specificity, defined as whether these investments are specific to a particular transaction or can also be used for other purposes, is considered as a key factor of investment. Additionally this theory highlights two behavioural assumptions as acknowledging that humans have bounded rationality and some are prone to opportunism. Baker et al. (2002) supplemented this theory through the introduction of the option for cooperation. Transaction costs can be important to assess when looking at commercial relationships related to sustainability challenges, as adding responsibility for managing sustainability challenges into transaction decisions can change the balance of costs and benefits for outsourcing (Sarkis et al. 2011).

SCM research also highlights interdependence buyers and suppliers can have on each other and draws attention to the fact that lead firms cannot always take unilateral decisions. Research using a relational view considers inter-organisational connections as a way to get access to critical network resources (Dyer and Singh 1998). A related perspective is resource dependency theory, which sees firms as requiring critical resources from their suppliers, such as standards, technologies, materials and distribution channels (Tachizawa and Wong 2014).

Within SCM research two further theories are useful for helping to understand how firms interact with each other. Information theory, considering information asymmetry and signalling (Sarkis et al. 2011), is a concept that is relevant when looking at interactions between diverse actors. Additionally, agency theory can be used to explore incentive mechanisms (Carter and Rogers 2008; Tachizawa and Wong 2014).

\section{Lead Firm Governance Across Multi-tier Supplier Relationships}

While early research on lead-firm governance focused on relationships between lead firms and first-tier suppliers, a growing body of research on sustainability challenges is emerging that considers relationships across multiple tiers. SSCM studies using this approach can be roughly divided into those that explore types of connections and those that consider mechanisms that promote change.

Mena et al. (2013) identified three forms of connections between lead firms and second-tier suppliers in multi-tier SSCM (MT-SSCM) as open, meaning there is not a direct relationship, transitional, meaning a link is being developed and closed, meaning that a formal relationship exists. Tachizawa and Wong (2014) provide further insight into understanding the types of connections that lead firms can use to govern lower-tier suppliers by identifying four basic approaches as 'Direct', 'Indirect', 'Work with Third Parties' and 'Don't Bother'. Grimm et al. (2014) identify notable differences in lead firm connections with lower-tiers compared to direct suppliers as involving a lack of contractual relationship, limited ability to exert direct pressure and incomplete knowledge of identities of lower-tier suppliers.

Another perspective is provided by Hofstetter (2018) who identifies five approaches for how lead firms can connect to lower-tier suppliers in MT-SSCM. One is having the first-tier supplier take responsibility. The second is connecting directly to the lower-tier supplier without involving the upper-tier supplier. The third is interacting jointly with the upper and lower-tier supplier. The fourth is attempting to influence the lower-tier supplier's local environment. The fifth is changing the structure of the supply chain to develop a formal, direct link with the lower-tier supplier. The most popular approach identified by Hofsetter was working through first-tier suppliers. Hofstetter posits that lead firms generally only take the second or third approach as a last resort. The fourth approach can be used when major issues arise that concern whole regions and can often involve working with partners, such as NGOs or other lead firms. The fifth approach can be a drastic step but can help to deal 
with persistent challenges and create benefits compared to competitors that do not have such direct connections.

When considering how lead firms can influence lowertier suppliers from a MT-SSCM perspective, Klassen and Vereecke (2012) identify two main capabilities from existing research as monitoring and collaboration, and identify a third option, through their empirical research, as innovation. They consider innovation capabilities as focusing on developing new processes within the supply chain that bring in new stakeholders. Tachizawa and Wong's (2014) connection types were associated with different influence mechanisms. 'Direct' involves providing specific requirements that lower-tier suppliers must meet, choosing lowertier suppliers, sharing information directly with lower-tier suppliers or providing assistance, such as training, running conferences or carrying out joint applied research. 'Indirect' approaches involve giving requirements to first-tier suppliers or requiring third-party certification for lower-tier suppliers. 'Working with Third Parties' can involve supporting firsttier suppliers to develop monitoring systems for lower-tier suppliers, using third-party information to monitor lower-tier suppliers, collaborating with NGOs or competitors or delegating responsibility to a third party. 'Don't Bother' involves having limited information about lower-tier suppliers and not seeking to change their behaviour.

To better understand MT-SSCM, Sauer and Seuring (2018) recently employed a perspective that aligns closely with GPN research. They draw attention to the need to look at the multiple institutional environments that exist across fragmented production processes. A challenge illustrated by this perspective is that when there are multiple distinct relationships between a lead firm and lower-tier suppliers, there may not be a common relational space. They see suppliers as active agents that may be in situations requiring reactions to potentially conflicting institutional pressures. Such situations can cause suppliers to decouple from supply chain structures not compatible with local pressures. In contrast, similar institutional pressure from vertical and horizontal sources facilitates compliance and cooperation.

While the buyer-driven governance perspective, which is prominent in GVC/GPN research, claims that lead firms govern entire supply chains, the processes through which this governance occurs have not been explored in-depth. Ponte and Sturgeon (2014) highlighted the importance of looking at diverse relationship across micro links involving commercial relationships between multiple tiers of buyers and suppliers. They question the role of lead buyers as driving all stages of production and introduce the idea of a spectrum from unipolar governance, with production driven by one key actor, to multi-polar governance, involving a variety of governance actors.

Within a GPN framework, a model that can facilitate the analysis of governance flows across fragmented production processes is provided by Alexander (2018). This approach identifies key structures that are important to consider in ESNs as the identities of the actors at the top of the network, the types of vertical links that connect network members, the types of businesses involved as producers and the locations of network members. These considerations are seen as important for understanding why particular production practices are being used and how to promote changes. A key insight from this perspective is that, within an ESN, groups of producers within the same local productive system can have similar experiences and sustainability challenges and the converse that groups of producers in the same ESN working in different local productive systems can have different experiences and sustainability challenges.

While many insights can be drawn from SSCM literature, this paper is based in a GPN perspective. A key difference is that SSCM perspectives often consider sustainability from the perspective of the lead firm. This study however, looks at sustainability across the entire network. This involves questioning who defines sustainability challenges and whether potential interventions will feasibly address challenges and not just shift problems to different locations.

\section{Methodology}

This article is based on a qualitative case study, with the case defined as a network of interconnected lead firms and suppliers. Having a network as a case study provides an approach which differs from much research on SSCM as most empirical studies have focused on lead firms' and often not looked at even first-tier suppliers (Carter and Easton 2011). The main research question is as follows: Facing pressure to support sustainable production, how do garment sector retailers provide governance for sustainability across their fragmented ESNs? To answer this question, the paper considers how lead firms connect to members of their ESNs and the strategies they use to promote change.

Addressing the issue of sustainable production in the ESNs of cotton garments is important because of the largescale global impact of these networks' production processes. Cotton garment production can broadly be considered as being divided into cotton production, textile production and garment production. Millions of people worldwide are directly employed by these industries and even more feel the impacts when unsustainable practices are used. Specific social and environmental challenges in cotton garment production include occupational health and safety concerns, child labour, instability of income, discrimination of workers by gender and other classifications, high levels of water and chemical inputs in fibre production and textile treatments, improperly managed waste disposal, volatile commodity 
Table 1 Data sources

5 interviews with representatives of 3 retailers

66 interviews with 57 ESN suppliers

- 7 interviews with 5 first-tier sourcing intermediaries who have known connections to 12 of the UK's 2012 top 20 retailers

- 5 interviews with 5 lower-tier intermediaries

- 54 interviews with 47 producers (businesses engaged in cotton farming, ginning, yarn spinning, textile manufacturing, garment manufacturing and wet processing services)

27 interviews with additional stakeholders (industry support service providers, NGOs, government officials and other knowledgeable informants) Attending 8 industry events

Available annual reports, sustainability reports and websites of the UK's 2012 top 20 retailers (Arcadia Group, Asda, Debenhams, H\&M, House of Fraser, JD Sports, John Lewis, Marks \& Spencer, Matalan, N Brown, New Look, Next, Primark, River Island, Sainsbury's, Shop Direct, Tesco, The Edinburgh Woollen Mill Group) from 2013 to 2015

markets and a hugely uneven distribution of gains through the value chain.

The specific case study explored is the network involved in UK retailers sourcing cotton garments in India. UK retailers were chosen because of their prominent role in global garment sourcing practices. In 2012, the UK was the fourth largest global importer of clothing (UN Statistics Division 2015). Additionally, UK retailers have been major players in global efforts to address sustainability challenges within garment production.

Within the UK, the bulk of clothing is sold by a small number of large retailers. This study focuses on the top 20 businesses contributing to UK clothing sales in 2012. These firms were responsible for 58\% of national sales (Mintel 2013). Exploring the governance roles played by these firms provides insight into governance processes that cover a large set of producers.

As UK garment retailers often share the same suppliers, this study looks at a set of producers that are part of an interconnected ESN responsible for production for the same set of retailers. Production in India is focused on for multiple reasons. As one of the UK's top five sources of cotton garment imports, India is an important supplier of cotton clothing for the UK (UN Statistics Division 2015). Additionally, India provides a location where all stages of production occur within one country, which was important for being able to carry out the field work with the resources available.

The findings were developed through progressive focusing, an approach that involves "systematic narrowing and refinement of the research focus during fieldwork in order to accommodate highly unique and specific issues (emic) of socio-cultural behaviour (Parlett and Hamilton 1972; Stake 2010) (pp. 818-819)", which can facilitate theory refinement (Sinkovics and Alfoldi 2012). This involved a thorough review of relevant literature and collecting a large volume of empirical data and then consulting additional literature as patterns started to become apparent through the data analysis process. This approach helped to tie together the emerging qualitative empirical findings with debates in relevant literature.

Two main sources of data were used for this study (see Table 1). The first involved field research in the UK and India. This included a series of semi-structured interviews with representatives of garment retailers, their suppliers and other individuals connected to and knowledgeable about the case study network. A total of 98 interviews were conducted in the UK and India in 2013. Additionally, eight industry events in the UK and India were attended from 2012 to 2014.

Representatives of the UK's 2012 top selling garment retailers and members of their ESNs were approached as potential interviewees. In order to identify producers to approach for interviews, it was necessary to attempt to map out the businesses involved in the Indian portion of the case study retailers' ESN. Manufacturing cotton clothing involves multiple activities, with major steps including cotton farming, cotton ginning, yarn spinning, weaving or knitting textiles and garment manufacturing. Wet processing (which includes activities such as bleaching and dying) is also a key step that can be conducted at varying points in the production process and can be integrated in facilities carrying out other activities or conducted by independent service providers. Mapping businesses involved with these tasks included reviewing available data on trade flows of intermediary products used in making cotton garments, interviewing experts and asking identified ESN members in India about their buyers and suppliers. These inquiries revealed a large and complex ESN for which the resources were not available to completely map. However, locations where large amounts of production take place were identified and interviews were conducted with businesses in these areas. As lower-tier producers did not know the end users of their products, companies were interviewed in areas where it was likely that outputs were contributing to production for the case study retailers. Interviews were conducted with representatives from three top 20 UK retailers, five sourcing 
firms that work for multiple firms among the UK's top 20 retailers, 5 lower-tier sourcing intermediaries and 47 producers. Supplier interviews included businesses involved in all stages of production.

Interviews were semi-structured and approximately 45 minutes long. They were based on lists of pre-defined topics customised for each type of interviewee and modified as the research progressed and new topics of interest emerged. Using a method of inquiry based on institutional ethnography, the approach used in the interviews focused on learning about a global network through the informants' lived experiences (Smith 2005; Ng and Mirchandani 2008). Seventy-two of the interviews were conducted by the primary researcher in English and 26 of the interviews were conducted in regional languages (Hindi, Gujarati and Tamil) by interpreters in the presence of the primary researcher. While most of the interviews were conducted in person, 11 of the interviews were conducted over the phone or through Skype. Interviews were recorded with the consent of participants. ${ }^{1}$ The English recordings were transcribed directly. The interviews conducted in other languages were translated and transcribed into English. Independent speakers of the original languages were hired to check the accuracy of the translations.

The second source of data was sustainability-related material published from 2013 to 2015 by the 20 retailers included in the case. Texts reviewed included content published on websites, annual reports and sustainability-focused reports. This material was chosen as it provided an overview of recent activities being carried out and planned.

These sources of data provided rich qualitative information about firms' practices. A systematic and trustworthy approach to data analysis was facilitated by using computer software (Sinkovics et al. 2008). Transcripts and texts produced by retailers were reviewed and coded using NVivo with a focus on identifying instances where lead firms were found to be influencing or attempting to influence practices of suppliers. Separate instances were subsequently grouped into the five distinct governance mechanisms presented in this article. The groups were developed through an iterative process of analysing the findings and reviewing theories in literature. In the reported findings, interviewees' identities are kept confidential but firms' names are mentioned when information is derived from secondary sources.

\footnotetext{
1 Three interviews were not audio recorded due to unforeseen circumstances. Detailed notes were taken.
}

\section{Lead Firms' Governance Across Their Extended Supplier Networks}

This study identifies two key elements of lead firm governance for sustainability. The first is the type of path connecting lead firms to producers. The second is a set of mechanisms used to promote change. This section presents empirical results related to both elements.

\section{Governance Pathways}

Businesses in India responsible for different stages of cotton garment production are variously vertically integrated and fragmented. For example, one business may carry out multiple tasks, such as yarn spinning and textile weaving or can be limited to one task. Each business generally sells to multiple buyers and sources from multiple suppliers creating a complex network of vertical connections. In efforts to promote sustainable production, retailers in the case study were found to use both vertical connections, found in existing buyer-seller relationships, and horizontal connections, purposefully created to address sustainability challenges, with actors in the local productive systems of lower-tier suppliers. Figure 1 illustrates examples of vertical and horizontal governance pathways for a cotton garment ESN and Table 2 outlines possible vertical and horizontal connections that can be used during lead firm governance processes.

\section{Lead Firms and Vertical Governance}

There are two ways that lead firms can promote sustainable processes in the early stages of production through their vertical sourcing relationships. One involves trying to promote changes through multiple connections in fragmented vertical pathways. The other is through working with vertically integrated suppliers.

Fragmented Vertical Pathways Garment production in India is typically carried out through fragmented vertical pathways, with intermediary components of garments passing through multiple buyer-seller relationships. A fundamental challenge with this type of system is that lead buyers do not have direct commercial connections to lower-tier suppliers. A particular challenge with information flowing through these paths in this case is that, in the lower-tiers, many transactions involve limited to no connection between buyers and suppliers. Some transactions are carried out through intermediaries and others involve auctions. These sales are usually based on observable product qualities.

Adding process requirements to the sales of these products would be in effect turning them into credence goods, which are items that are considered to have value based on 
Fig. 1 Vertical and horizontal governance in a cotton garment extended supplier network
Table 2 Vertical and horizontal governance pathways

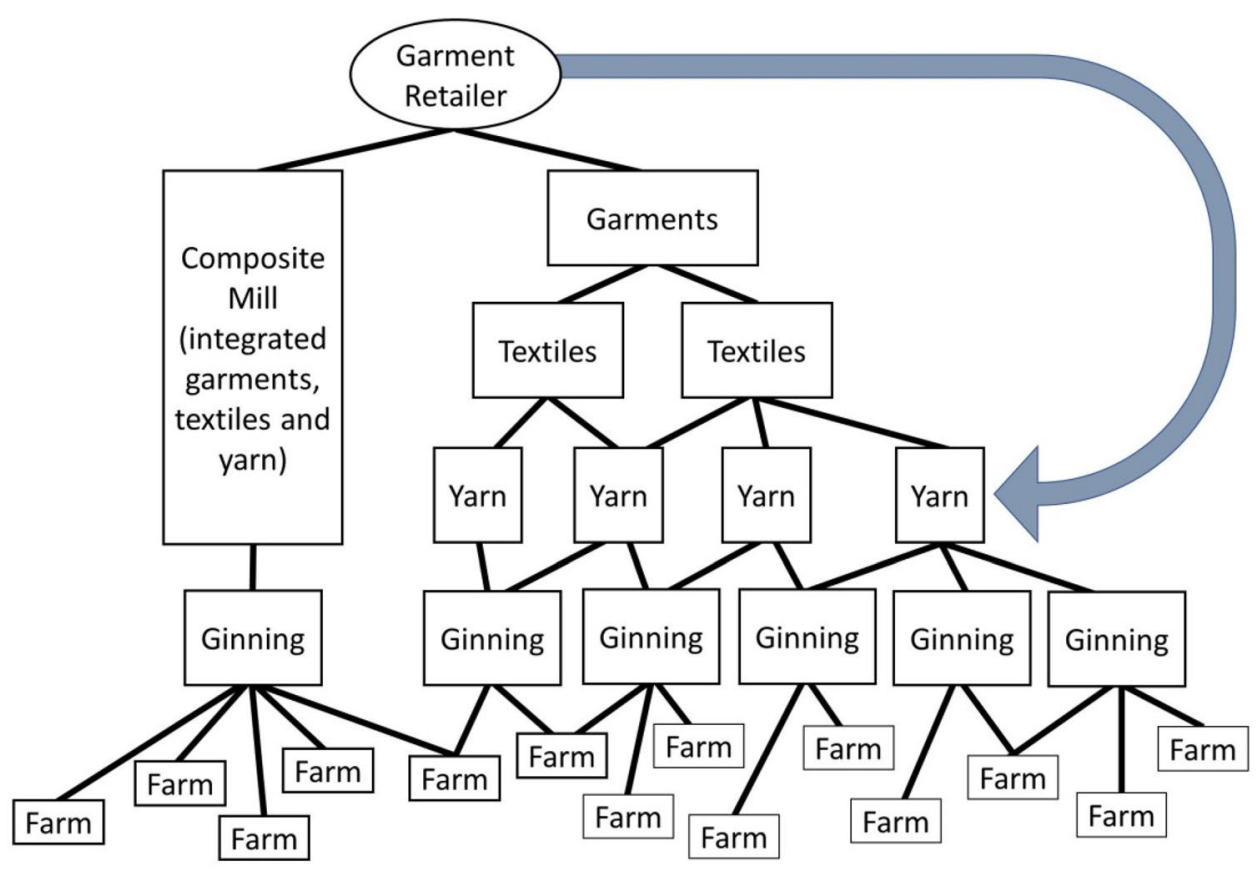

Potential Vertical

Potential Horizontal

Governance Path

\begin{tabular}{ll}
\hline Vertical pathways & Horizontal pathways \\
\hline Highly fragmented pathways & Direct to lower-tier producers \\
Connections to vertically integrated producers & Connections to governance actors in local regions \\
& Presenting information publically (online) \\
\hline
\end{tabular}

qualities that cannot be directly observed by a buyer (Feddersen and Gilligan 2001; Darby and Karni 1973). A challenge with credence goods is the inability for a buyer to directly assess the credence values. To pass information on about unobservable qualities, each transaction could involve providing assurances to each subsequent buyer or new certification systems could be developed.

Currently, at a small scale, there are some early-stage inputs specifically identified as having more sustainable production processes flowing through top retailers' ESNs. However, these are often niche product lines, such as organic or recycled cotton. Monitoring production for these products and their movement through supplier networks is currently costly as it often involves dedicated monitoring for traceability and consumers usually pay a premium to cover these costs. Expansion of certifications for lower-tier production for all cotton garment inputs would require dramatic upscaling of certification processes. This would be very challenging as can be seen by the failed attempt of Marks and
Spencer to carry out a traceability programme that solely involved tracking intermediary stages of cotton garment production without instigating changes in production practices. The company hired to perform this exercise attributed the failure to the complexity of the network and the informality of trading relationships in global cotton garment production (Barrie 2014).

However, several of the case study retailers were found to be expanding their code of conduct requirements to cover secondtier suppliers such as laundries, embroidery units and packaging suppliers. These policies represent an expansion of UK retailers' previous focus on first-tier garment manufacturing.

One example of this development is Marks and Spencer's 2014 policy for addressing issues related to pollution in wet processing. This policy may be difficult to enact as a representative from a retailer interviewed for this study indicated that wet processing firms have historically been resistant to lead firms' inspections (Retailer A, India-based CSRfocused representative). Making changes to waste treatment 
facilities can be expensive and firms may not be willing to invest in these changes depending on what proportion of their potential output would be affected by such requirements. Additionally, as retailers do not have direct contracts with wet processors that are not integrated into textile or garment production and Marks and Spencer's policy requires the wet processors to provide proof of their own third-party certification, space is created for corruption.

A second example of a vertical approach being used to address sustainability challenges in second-tier suppliers can be found in retailers attempting to regulate working conditions for homeworkers who can be responsible for irregular activities carried out by hand for garments that are made in factories, such as beadwork. One interviewee described the expansion of retailers' policies in this area as follows,

We are working on issues such as homeworkers, where the beads and the sequins get attached on womens wear dresses and tops which are being outsourced by the manufacturers out to the homes through subcontractors... we actually go out to those people also and go out to the homes and ensure that the code of practice is implemented there also (Retailer A, India-based CSR-focused representative).

Another way that lead firms can shape production practices of lower-tier suppliers is through processes of nomination. In nominated production, retailers directly choose the inputs that their contracted garment manufacturer will use. In these cases, retailers may have direct contact with lowertier producers and can require the producers to pass code-ofconduct inspections. However, nomination of fabric sources is not very common in the Indian context (AEPC 2009).

In many industries companies often do not know which businesses are involved in lower-tiers of production. Limited information can flow between firms, particularly when it comes to sensitive issues and small firms may not have the resources to comply with disclosure requirements (Kim and Davis 2016). Tracking inputs down to raw material is difficult for many products. In an empirical study on conflict minerals, Kim and Davis (2016) found that most companies they spoke to in 2014 and 2016 were unable to determine the country of origin of some of their minerals.

Vertically Integrated First-Tier Suppliers In contrast to using highly fragmented production processes, lead firms have the option to work with vertically integrated producers. While this model was found in the field work for this case study, it is rare in India. For lead firms, connecting to vertically integrated producers can limit the risk associated with the loss of control created by fragmented production without losing the benefit of flexibility created by not directly owning production facilities. Such systems allow for easier monitor- ing of activities at earlier stages of production compared to highly fragmented production.

A challenge with this type of connection is that vertically integrated suppliers may have business structures that rely on production activities taking place across multiple locations, with separate management teams using different practices. Major UK retailers have sustainability policies, such as codes of conduct, which are expected to be enforced for first-tier suppliers. When working with vertically integrated suppliers, these suppliers in theory would be expected to uphold retailers' sustainability policies for all stages of production carried out in-house. However, vertically integrated producers in India carrying out production at different sites have been found to only have monitoring and certification for their garment manufacturing facilities (Theuws and Overeem 2014).

A benefit of working with vertically integrated suppliers is that large first-tier suppliers can partner with lead firms to address sustainability issues among lower-tier suppliers. This model is found in the relationship between Retailer B and Composite Mill A who have developed a partnership to promote sustainable cotton farming processes. Retailer $\mathrm{B}$ is a UK department store. Composite Mill A is a vertically integrated Indian producer that internally carries out spinning, weaving and garment-manufacturing activities, known as a composite mill. Through this partnership, Composite Mill A supports programmes that train farmers on more sustainable practices and directly buys the cotton and pays for gins to process it.

While this project has been relatively successful, the programme involves a high level of commitment and work for Composite Mill A. Within Composite Mill A, the project is run by a department that has been set up specifically to focus on sustainable cotton. This type of programme is possible due to the large size of Composite Mill A with 25,000 employees and their vertically integrated business structure. Additionally, Retailer B is a brand that places large orders, includes sustainable production as a large part of its marketing strategy and has been willing to invest a significant amount of work into this project. While commercial pressures have historically encouraged outsourcing and highly fragmented production, it is possible that needs related to sustainable production could create increasing pressures for vertical integration.

\section{Lead Firms and Horizontal Governance}

Lead firms are developing new types of non-sourcing connections in efforts to address sustainability challenges at different stages of production. These can include direct connections to lower-tier producers, working with partners connected to local productive systems housing lower-tier producers or creating public campaigns seeking to reach 
lower-tier producers. Governance in these connections is less formalised than sourcing policies and often is limited to individual projects.

Direct interfirm connections between retailers and lowertier producers to address sustainability issues were not found in the research for this study. However, this does not mean that these connections do not exist. The examples discussed below involve retailers connecting to lower-tiers through building connections to governance actors in local productive systems and through creating public campaigns targeted at lower-tier producers.

Lead Firms Connecting to Governance Actors in Local Productive Systems When lead firms make horizontal connections to governance actors in local productive systems that house ESN producers, such as NGOs, governance partners can work to address sustainability challenges within communities or regions. While this type of project is often on a small scale, it can involve ongoing support from retailers and collaboration within local productive systems. A benefit of this approach is that it allows for an in-depth focus on targeted sustainability challenges. Projects involving horizontal connections have greater potential to be developed in ways that take into account local dynamics. Considering production at the scale of local productive systems allows for an understanding that producers face multiple governance pressures including those felt vertically through connections to multiple buyers along with those felt horizontally within the local productive system in which they are located. Local governance systems have a balance between public, private and social governance (Gereffi and Lee 2016) and often have civil society actors trying to address sustainability challenges that are felt locally.

The case study retailers are involved in several projects targeted at addressing local sustainability issues in India, including supporting schools or hospitals in communities where factories are located as well as supporting NGO projects that provide different types of training and support services for workers. The ways that retailers engage in non-sourcing connections differs between retailers much more than sourcing practices differ. Working with NGOs and MSIs, some retailers play leading roles in multiple sustainability-focused projects with involvement in design and implementation and others' involvement is limited to financial contributions. While the scope of these projects can vary from being based in one community to large international projects, the bulk of projects involving connections with lower-tier producers in India are small scale.

One challenge with making direct non-sourcing horizontal connections with local productive systems is being able to connect with key local governance actors. This can be difficult due to the diversity of governance systems across a complicated network and that some local productive systems may lack strong local governance actors who could be potential partners. Also, the diversity of local productive systems and sustainability challenges they experience, even between different local regions producing the same components, would make it very difficult for lead firms to scale up efforts that involve creating horizontal connections.

An example of a major project using horizontal connections, which UK garment retailers have been involved in and which explicitly involves a consideration of global differences between local productive systems, is the Better Cotton Initiative (BCI). This large MSI works on promoting sustainable cotton worldwide and has branch offices in cotton-producing regions. Local affiliates work directly on the ground to train farmers to use more sustainable practices. The purpose of this programme is to create changes in farmers' production practices in a way that addresses local sustainability challenges. The programme relies on attracting farmers to voluntarily participate in the support services they offer. Farmers enrolled in this programme are taught methods which are supposed to result in increased profit along with decreased environmental impact and better working conditions.

Online Connections to Suppliers Lead firms have also developed publicly available resources which are designed to directly reach lower-tier producers. For example, New Look has developed the Textile Industry Sustainability Platform (TISP), a multi-brand initiative that provides online resources for Chinese textile factories seeking to decrease their environmental impact. This is a free resource supported by seven leading global brands and three consultancy companies. The guide promotes the business case for energy efficiency, introduces energy management and provides examples of how firms have improved energy efficiency.

\section{Five Mechanisms Employed in Buyer-Led Governance for Sustainability}

Cutting across approaches that use both vertical and horizontal connections, a useful way to breakdown governance pressures is between those that create incentives for producers to voluntarily change behaviours and those that involve mandatory pressures. At some points in ESNs, mandatory enforcement is possible and at other points there may be no governance actors able to implement mandatory regulations. Another issue is that the nature of some sustainability challenges can be resolved with simple changes and others require more complex adaptation to businesses' systems (Alexander 2018). Understanding that diverse sustainability challenges within an ESN may have different answers to these questions, leads to the need to employ multiple governance approaches. In this context, lead firms' emerging 
attempts to provide governance for the diverse sustainability challenges across segments of their ESNs have begun to take different forms. Five model mechanisms can be identified through which retailers are attempting to play a role in governance for sustainable production.

\section{Hierarchical}

The first mechanism, considered as Hierarchical, involves lead firms carrying out production themselves. This involves having complete control over the processes used. However, this is a strategy that is rarely employed by the case study retailers. A related example found in this case is when retailers choose to work with vertically integrated suppliers. These producers have complete control over early stages of production.

\section{Compliance}

The second mechanism can be seen as actions fitting within Lund-Thomsen and Lindgreen's (2014) compliance paradigm. This Compliance mechanism involves lead firms setting standards and checking if suppliers are meeting them. This has been the most common approach for addressing issues related to working conditions in garment factories. An option for using a Compliance model with a horizontal approach could involve retailers partnering with key governance actors in a local productive system who could manage a compliance system.

The Compliance model can involve incentives or sanctions. Scott (2014, p. 159) discusses the effectiveness of coercive models as depending on,

relatively clear demands, effective surveillance, and significant sanctions. Beyond this, it also matters whether the mechanisms employed are primarily those of power, involving imposition of authority-where the coercive agent is viewed as a legitimate agent of control—or rely on the use of threats or inducements.

These factors can be seen as important for the compliance model.

Existing uses of the Compliance approach face a number of challenges (Lund-Thomsen and Lindgreen 2014). A common problem is failing to consider differences in local productive systems (Bartley 2010). Mezzadri (2014) emphasises that diversity among India's garment production centres creates unique challenges preventing universal compliance programmes from being effective. Lower-tier producers in this case work in even more diverse local contexts.

Another concern is that compliance is a tool that buyers use to exert control over their suppliers. Using a Compliance approach can reinforce unequal balances of power between buyers and sellers (De Neve 2009; Mezzadri 2014). Forcing producers to use practices dictated by their buyers can lead to modified practices creating new sustainability challenges (Lund-Thomsen and Nadvi 2010). Compliance systems can also lead to situations where suppliers actively try to evade inspectors or restructure systems in ways that exclude practices from inspections without actually alleviating sustainability challenges.

A further challenge of the Compliance approach is that it is particularly difficult when compliance criteria are related to processes. In contrast to product requirements that can be observed, process standards require monitoring, which can be especially difficult when production does not take place at integrated sites. Monitoring to enforce process requirements can involve a variety of options, which include directly monitoring production activities, or relying on a lower tier supplier, third-party monitoring or supplier self-evaluation. Empirical studies have shown lead firms' attempts to use the compliance model to influence first-tier suppliers have had limited effectiveness (Locke 2013; Barrientos and Smith 2007).

Finally, the Compliance model faces challenges related to the high level of resources required. Retailers' staff which are focused on enforcing codes of conduct for garment manufacturers are currently struggling to successfully carry out this task. Expanding their role to include compliance for lower-tiers may result in spreading already limited resources too thin. A retailer representative involved in enforcing a compliance system cites the ongoing challenges in the firsttier as a reason why retailers should not focus on lower-tier suppliers.

Our priority is to get our first-tier sorted out actually... For example, in India there are a lot of issues at the manufacturer's level in terms of the contract labour and the exploitation that comes with the contract labour, the minimum wages, all that, so that becomes the priority for us. There's no point in going to the second tier or the third tier when the first-tier is actually not compliant. So that's a challenge (Retailer A, India-based CSR Manager).

A significantly higher number of businesses are involved in an entire ESN compared to the group that would be considered first-tier suppliers. Increased expenses involved in expanding compliance systems to lower tiers would not only be for the lead firms but also for lower-tier buyers and producers which may be expected to invest in participating in certification systems.

\section{Support Services}

The third mechanism of Support Services can be seen as a component of Lund-Thomsen and Lindgreen's (2014) 
cooperation paradigm as it involves more cooperation than the compliance model. This mechanism involves lead firms encouraging producers to use more sustainable processes through providing assistance.

The Support Services approach can involve a variety of instruments. These can range from forms of capacity building such as training sessions for management or workers to financial support for equipment upgrading. In terms of providing training, some retailers now have inductions for all suppliers, which can be offered in conjunction with a variety of ad hoc training and support programmes to first-tier suppliers and their employees. Support services can also involve the creation of support materials which guide suppliers on how to fulfil requirements of codes of conduct. An example of how the Support Services model is being used through horizontal connections can be found in John Lewis' involvement with a financial literacy training programme in India.

A challenge with training programmes is that they can become tick-boxes for producers. In these cases, staff may attend training sessions but continue to use existing practices without incorporating the changes being promoted. A respondent in this study described that,

All big brands [are] paying for training... But the factories are having less interest in this type of training. Because... they are thinking that 'I know everything'... [It's] the same fault with us, we were doing this [training]... [the factories] were thinking that if the manager will go for one day there will be a loss of work but they were not able to see the benefit of it in the long run.... because the brand is forcing, they are sending their staff for the training... They're coming back [to their factories] and doing nothing but at least some is going. If you take some medicine and you vomit, not all will go out. Definitely some of the tablet will be inside your stomach (Auditing Firm B, Indiabased Country Manager).

In addition to formal training sessions, production staff can receive informal advice on how to improve systems. Amengual (2010) describes informal methods through which inspectors inform staff in factories being inspected as to ways that other factories have met compliance requirements. This informal information sharing can be an effective way to improve production practices.

\section{Partnership}

The fourth mechanism is Partnership, which can also be seen as fitting within Lund-Thomsen and Lindgreen's (2014) cooperative paradigm. This approach involves lead firms working with producers to collaboratively address sustainability challenges. An example of a partnership model can be found in the relationship between Retailer B and Composite Mill A discussed above.

The Partnership approach can be used directly within a buyer-supplier relationship or involve multiple partners. In the Partnership model, the priorities of multiple partners can be brought together. Soundararajan and Brown (2016) write about the benefits of finding shared value between buyers and suppliers. Initiatives which are related to motivations of both buyers and sellers may be able to tackle more complicated sustainability challenges. Considering the potential conflict between garment manufacturers' priorities compared to their own, some retailers in this case are starting to develop more cooperative ways of addressing working conditions with their first-tier suppliers.

While partnerships, and particularly multi-stakeholder partnerships, seem to be a very promising model for addressing sustainability challenges they face several key obstacles. One is that there may be problematic power imbalances between the partners (Lund-Thomsen and Lindgreen 2014). Another is that they can require a lot of effort to maintain. Considering the feasibility of developing partnerships with a broad set of first-tier suppliers, Lund-Thomsen and Lindgreen (2014, p. 17) noted,

The rhetoric surrounding cooperation sounds valid, but it is difficult to imagine how vast corporations such as Nike can realistically engage in close cooperation with more than 800 first- tier suppliers. Collaboration might be feasible with a few selected suppliers, engaged in pilot projects; it appears nearly impossible to replicate such close cooperation across hundreds of suppliers, considering just the logistical challenges.

Lead buyers seeking to make partnerships with producers involved in multiple stages of production would face an even larger challenge as this would involve significantly more businesses.

\section{Promotion of Voluntary Change}

A fifth mechanism is the Promotion of Voluntary Change. Through the Promotion of Voluntary Change approach, new or modified production practices can be promoted to producers at any point in an ESN, even in situations where buyers have very weak to no connections with producers. Lead firms can promote new practices through a variety of methods which can involve working directly with suppliers, having partners promote new practices or creating public campaigns.

Two of the horizontal governance scenarios described above can be seen as using the Promotion of Voluntary Change approach. BCI and TISP involve presenting ideas to producers which they can choose to incorporate into their businesses. Promotion of Voluntary Change can also take 
place in vertical connections. One way for this to happen is when lead firms provide training programmes to first-tier suppliers that are designed to highlight practices that can voluntarily be adopted.

One challenge with this model is that addressing some sustainability challenges might not be in the producers' best interests, such as those related to distributive issues (see Locke 2013) and may require external enforcement. Nevertheless, the Promotion of Voluntary Change approach may be particularly useful in local regions which do not have strong key governance actors, for reaching producers who are in the lower-tiers of an ESN or for broadly disseminating information related to an innovative sustainable practice.

\section{Comparing Governance Paths and Mechanisms}

Each of the governance paths and mechanisms has different strengths and weaknesses. Lead firms seeking to address sustainability challenges in their ESNs make decisions on what strategies to employ. This section discusses factors that can shape these decisions.

\section{Vertical Versus Horizontal Approaches}

In this case, vertical and horizontal approaches are both being used with some measures of success. However, both approaches face challenges for connecting with lower-tier producers. Hofstetter (2018) highlights the expense and difficulty of mapping entire ESNs and identifies two ways for lead firms to identify high-risk areas in complex ESNs. One is trying to follow vertical paths and focusing investigation on particular areas of interest. The other, which is more aligned with horizontal approaches, is using economic trade data to gain an understanding of patterns. Ongoing technological developments are helping to facilitate new tracking systems.

Vertical approaches benefit from working with contractual relationships. However, these approaches may have limited reach and may not effectively promote change across local productive systems which have businesses selling to different types of buyers all contributing to a common problem. For instance, an issue related to pollution may not be well addressed with only a small portion of companies in the affected area receiving vertical pressure to change their waste management. Overall, vertical approaches can be enhanced by understanding that vertical pressures are felt in conjunction with horizontal pressures (Gereffi and Lee 2016; Humphrey and Schmitz 2000).

Horizontal approaches can benefit from connecting to a larger set of producers. However, these producers may not actually be contributing to the lead firms' ESNs. This may be better for addressing sustainability challenges but harder for lead firms to justify the use of resources. While horizontal connections to individual firms were not found in this study, lead firms could benefit from connecting to businesses which Yan et al. (2015) have referred to as nexus suppliers that play critical roles due to their inter-organisational ties.

Lead firm governance through both vertical and horizontal pathways reaches producers working in distinct local regions. In these spaces, private governance can be seen as compensating for a deficit in public governance (Mayer and Gereffi 2010; Gereffi and Mayer 2006). While this is often the case, there are times when public and private governance can complement each other (Amengual 2010). Lead firms must deal with local challenges whether using vertical or horizontal approaches.

\section{Comparing the Five Mechanisms for Promoting Sustainable Production}

The five mechanisms identified for promoting sustainable production can be used in conjunction with each other but have a number of key differences. Major differences are the amount of power a lead firm needs to use each mechanism, suitability for different types of sustainability challenges, who defines sustainability and who enforces the use of sustainable practices. Data collected indicate that in the UK garment industry, while the Compliance model dominated early attempts to govern for sustainability, the use of Support Services, Partnerships and Promotion of Voluntary Change has been expanding. Hierarchical production for the case study retailers is quite rare. However, measuring the exact prominence of each mechanism is not possible with the methods used in this study. An overview of key features of the five model mechanisms discussed can be found in Table 3.

\section{Suitable Structure for Buyer-Seller Relationship}

Governance actors need different levels of power for each mechanism. The first two mechanisms require some direct control over producers. The latter three approaches can be used in situations where governance actors do not have any direct control over producers.

Lead firms' involvement in any of these strategies depends on their connections with producers. The Hierarchical approach requires vertically integrated production and involves complete power over production. The Compliance approach is supported through relationships that involve a strong role of buyer governance. This approach often requires having direct power over producers. However, it can involve lead firms with limited powers over producers aligning with other governance partners that do have power to enforce compliance. Alternatively, Compliance approaches 


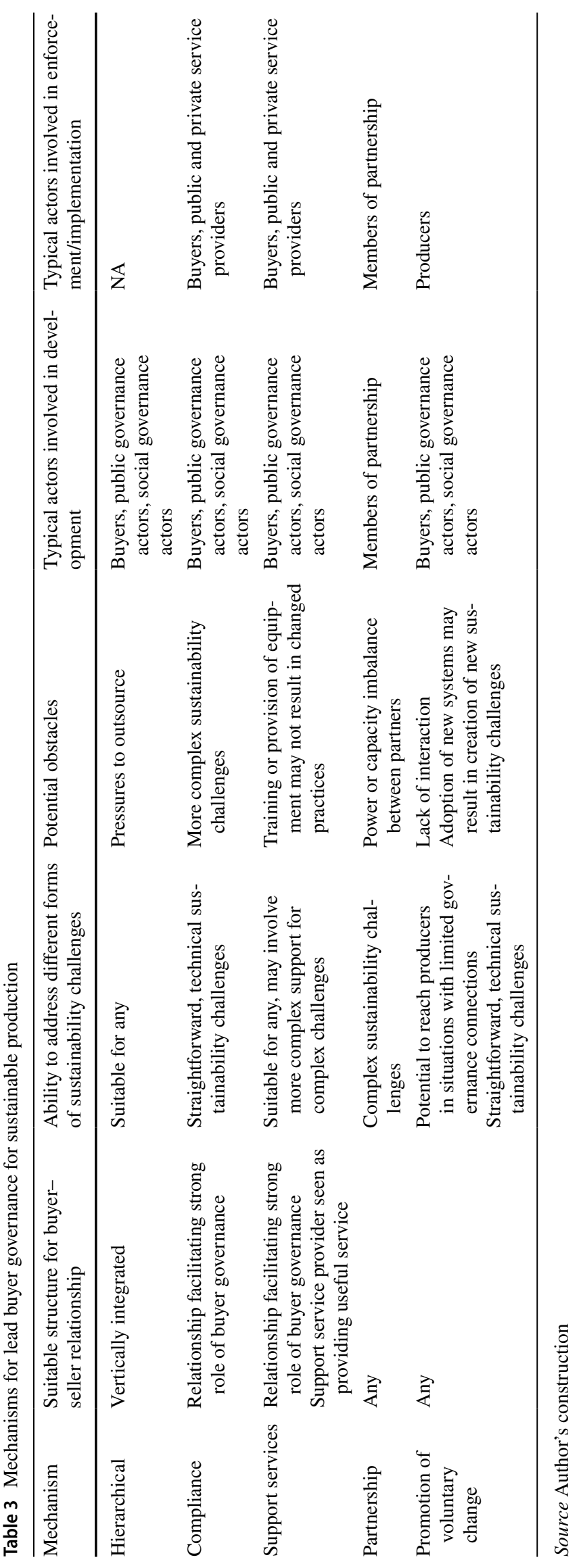


can be promoted as voluntary with producers deciding to join certification schemes in order to gain expected benefits. In this case, the approach could be considered a combination of the Compliance and Promotion of Voluntary Change models. Use of the Support Services mechanism can involve buyers having mandatory requirements for producers to participate or can also be used in situations where producers feel that the Support Services are worthwhile. The Partnership and Promotion of Voluntary Change models can be used in any relationship.

\section{Ability to Address Different Forms of Sustainability Challenges and Potential Obstacles}

Each mechanism has different potentials for addressing sustainability challenges and faces different potential obstacles. Hierarchy can address any sustainability challenges and involves complete control. Compliance is better for straightforward challenges and difficult to apply for complex challenges. Support Services are suitable for any sustainability challenges. However, a challenge in cases where resolving a sustainability challenge requires behaviour change, is that receivers of support may not change their practices. Partnerships are particularly useful for complex challenges but a difficulty can be power imbalances between partners. The Promotion of Voluntary Change model is beneficial for reaching producers in hard to connect to parts of ESNs. However, it is seen as being best suited to simple challenges. A weakness of this mechanism is that it can result in changes that do not address the sustainability challenge being targeted.

It is important to consider how potential alternate production practices can address sustainability challenges. Just creating a blanket policy saying producers need to change " $\mathrm{x}$ " behaviour can create unexpected consequences. Identifying forms of governance that are compatible with producers' local experiences of multiple governance pressures can be more useful.

The prevailing structure of productive systems may be based on historical trajectories and may not be in the ongoing best interests of producers and other actors (Wilkinson 2003). In these cases, promoting change can be more acceptable to producers. In some cases, this can be related to the introduction of new technologies.

A representative from a retailer discussed the need for using multiple approaches to governance for sustainability. He described challenges with relying on a Compliance model for complex challenges and the potential benefits of using the Support Services and Partnership models.

Unfortunately, we've pushed auditing... but... the key issues that needed to be dealt with: worker-management dialogue, freedom of association, wages, etc., auditing has just never had the capacity to deal with those. Those are the kind of [issues] where you're not able to pick it up on a checklist. Auditing is like a 60 billion dollar business a year... Yet, if you look at the impacts in the last 10 years, it's been very minimal, very!... [Retailer A] has been at the forefront of this saying, "go beyond auditing"... there's a lot of issues... that will never be properly addressed because they've never been able to be picked up and the only way you're going to be able to resolve those is to ensure that the responsibility goes back into the workplace, for the workers and the management, to be able to negotiate effectively... giving workers the skills, the training, awareness and management the skills and training for being able to work with each other to address the issues within the factory but also to have mature industrial relations... instead of just getting a third party to go and visit a factory... We're building the relationships more with the unions and the NGOs and the other industry players, saying, "look, you know, you need to have the right management systems, workers need to have a grievance procedure, etc." but... it can't be that somebody just gives you a management system handbook and says put that in your factory... It has to be done properly and there has to be buy-in... I would say, we've let the workers down quite a lot because in auditing, we promised a lot but delivered very little (Retailer A, UK-based CSR Manager).

However, it is not always clear what mechanisms may be best to address a particular challenge. While challenges that are based on physical technology may be less connected to deeper culturally embedded practices and easier to address, Bartley (2010) points out that it is not a clear distinction between social challenges being complex and environmental challenges being simple and 'technical'.

For sustainability challenges which involve high levels of pressure to maintain current practices (sticky challenges), higher levels of cooperation and deliberation involving multiple stakeholders may be necessary to develop new systems which actually address these challenges. This is particularly important as externally driven pressures to address these challenges can just push the problematic behaviour out of sight.

\section{Development and Implementation of Interventions}

Humphrey and Schmitz (2001) draw attention to the contrast between who defines governance interventions and who enforces them. There are multiple possibilities across the five mechanisms. For Hierarchical, Compliance, Support Services and the Promotion of Voluntary Change models, there is potential for multiple actors to be involved in 
developing an intervention. This can range from lead firms internally setting priorities to broad stakeholder consultations. The only model that specifically involves producers in developing a strategy is the Partnership model. Partnership approaches are developed and implemented by members of the partnership. However, in practice, some partnerships involve relationships, with high power differentials, that do not actually allow all partners to contribute to designing strategies.

Often civil society groups are drivers for addressing sustainability challenges. A representative from a retailer's India-based code of conduct team spoke about the potential for NGOs to shape the firms' sustainability agenda, "It does happen that NGOs will come and approach us and they will say, 'we're doing', let's say 'child labour eradication from the supply chain, so would you be interested' and then we would deal with the proposals (Retailer A, India-based CSR Manager)". However, in many cases NGOs have been unable to stimulate change. Despite input from multiple stakeholders, often lead firms decide what type of sustainability issues they want to address and what approach they want to use.

Implementation strategies are based on the type of mechanism. Implementation of the Compliance and Support Services models can involve the buyer or public or private service providers. The actors involved in implementing a plan developed through a partnership would depend on the design of the strategy developed. Producers are responsible for implementing practices encouraged through the Promotion of Voluntary Change model.

Enforcement mechanisms differ greatly across these mechanisms. In the Hierarchical model, the lead firm designs production systems and hires people whose job responsibilities include working within these systems. In the Compliance model, lead firms, private third-parties, government monitors or even supplier self-evaluation can be responsible for ensuring the producers meets the required standards. In the Support Services model, there is often little enforcement over whether the new skills or technology are actually integrated into a producer's systems. In the Partnership model, each actor could be responsible for themselves or a monitoring system could be developed, depending on the strategy used in the partnership. In the Promotion of Voluntary Change model, changes by producers are not enforced by outside actors.

\section{Choice of Path and Mechanism}

A key factor when choosing an approach is the nature of the challenge a lead firm is seeking to address. Multiple methods exist for identifying sustainability challenges in ESNs (Guinée et al. 2011; Kühnen and Hahn 2018). The firms in this study seem to have an ad hoc approach in the choice of challenges they seek to remediate. Often actions are reactions to stories in the media or pressure from NGOs. Carter and Rogers (2008) highlight the importance of businesses taking into account economic, social and environmental factors when they seek to have SSCM, noting that much research focuses on social and environmental aspects. To develop globally sustainable production systems, operationalising systemic methods for identifying pressing challenges caused by activities in ESNs is an important step. A key consideration in this process is who defines the nature of the challenges as these can be seen differently by diverse stakeholders (Alexander 2018).

Mechanism choice is dependent on lead firms' power over producers. Power is shaped by the relationship between the buyers and suppliers along with the firms' network locations and consequently how much pressure exists to maintain current practices vs. the difficulties that would be involved in changing current practices. Lead firms with high power over their top-tier suppliers have been able to enforce straight forward changes through the Compliance mechanism. However, lead firms using this model have had more difficulty promoting changes that require more complex behavioural shifts. When looking at governance of lower-tiers, lead firms may have less power to mandate and persuasive approaches may need to be considered.

Combining governance mechanisms can be beneficial in some situations. Evidence has been found that combining the Compliance model with the Support Services model through running capacity building programmes simultaneously to implementing codes of conduct can address limitations of approaches purely based on compliance (Locke 2013). A study by De Marchi et al. (2013) finds that mentoring approaches, which can be considered as a combination of Support Services and Partnership, may be a good choice when suppliers are smaller and cannot afford certification. The study also showed a benefit of this approach can be enabling the co-development of environmental innovations.

Additionally, for any of the mechanisms, support from intermediaries may be needed. As new approaches develop, new forms of intermediaries can develop. This has already been the case for Compliance and Support Services, which have been popular approaches that now involve many specialised external service providers, such as social auditors. Jooste and Scott (2011) describe the creation of enabling fields which can connect potential intermediaries with existing skills to new initiatives that can benefit from these skills. Additionally, De Marchi and Grandinetti (2013) find that external knowledge, accessed through universities, research institutions and competitors, can play a large role for innovations related to sustainable production.

Another consideration is that lead firms facing pressures to produce sustainably can seek to change the structure of their networks. Related decisions can involve the processes outlined in the transaction cost economics model. In recent 
decades many firms made decisions to outsource. These decisions have led to current systems involving many sustainability challenges, such as production taking place in countries with weak or weakly enforced labour and environmental regulations. As sustainability considerations begin to play a larger part in lead firms' decision making, it remains to be seen how this will affect connections with suppliers.

However, lead firms' ability to change the structure of ESNs may be limited. Considered as CASs, these large and complex networks cannot be directly controlled. Lead firms' market-based decisions involve rapidly changing product offerings which necessitate relying on numerous producers with various specialties. Many lead firms are actively trying to reduce the sizes of their supplier bases. However, even with dramatic reductions (see Schüßler et al. 2018)lcompanies in the case study still have hundreds of first-tier suppliers supported by networks of thousands of lower-tier suppliers. Attempting to make targeted changes within these networks can involve a lot of uncertainty.

Synergies may exist between lead firms' sourcing practices and the type of governance for sustainability in which they engage. Lead firms which engage in process monitoring to ensure quality standards can more easily incorporate monitoring related to codes of conduct as these buyers already have a presence in their suppliers' factories. For lead firms that do not directly monitor production and for stages of production that do not involve custom-made products, current relationships between buyers and suppliers may be weak or non-existent. These sourcing models may be less conducive to developing partnerships or even providing support services.

Multiple frameworks provided by SSCM literature can be used to aid in choosing how to promote sustainable production. Notably, Tachizawa and Wong (2014) identify contingency variables that shape the approaches lead firms take as: power, stakeholder pressure, industry, material criticality, dependency, distance and knowledge resources. Additionally, the four groups of MT-SSCM critical success factors proposed by Grimm et al. (2014) can be used to evaluate potential interventions. The first group is lead firm-related or internal, which includes the lead firm having knowledge about its supply chain. The second group is relationshiprelated, which includes lead firm buyer-power (over direct supplier), direct supplier buyer-power (over sub-supplier), trust between the lead firm and the direct supplier, trust between the direct supplier and the sub-supplier and the existence of a committed long-term relationship between the direct supplier and the sub-supplier. The third group is supply chain partner-related, which includes the direct supplier's willingness to disclose sub-suppliers, involvement of the direct supplier, perceived value for the direct supplier, perceived value for the sub-supplier, low risk of supplierby-passing (involving the lead firm cutting out the direct supplier and sourcing directly from the sub-supplier, also known as disintermediation) and the sub-supplier's capability to comply with requested sustainability standards. Finally, the fourth group is context-related, which includes geographical distance between supply chain partners and cultural distance between supply chain partners. They note that further research is needed to better understand how dynamics of these factors can lead to success.

Also notable is the multi-level framework developed by Sauer and Seuring (2018), which is designed for choosing between Tachizawa and Wong's (2014) MT-SSCM practices. Three drivers of uncertainty in lead firm's relationships with suppliers are identified in the framework. First, members of an ESN experience pressure from being in the network and from their local environments (vertical and horizontal pressures). Second, the lead firm has uncertainty in maintaining secure supply. Third, suppliers experience demand uncertainty. Levels for these three types of uncertainty are measured as low or high to identify eight model situations that can guide the type of practice a lead firm should use for MT-SSCM.

While forms of buyer-driven governance are fundamentally shaped by behaviour of lead firms, in order to really address sustainability challenges more voice needs to be given to actors in lower-tiers, who may be the ones facing the consequences of sustainability challenges. Different industries currently face varying pressures related to raw material sustainability. However, as these issues tend to be driven by scandals, any industry could be the next one to face public pressure. Proactive lead firms can assess activities in their own supplier networks to determine where key challenges lie and base their actions on the needs of the people working in their ESNs and the communities affected by their practices.

\section{Conclusion}

The governance for sustainability model presented in this paper helps to explain the current and potential roles that can be played by lead firms seeking to promote sustainable practices across fragmented production processes. Key past lead buyer governance models have viewed the role of lead buyers differently. In the buyer-driven model, lead firms are seen to control access to major resources (Gereffi 1994). In the Gereffi et al. (2005) governance model, lead firms are seen as playing different roles depending on features of transactions. The modular approach developed by Ponte and Sturgeon (2014) identifies the potential for variable levels of power by lead buyers but does not identify the diversity of roles played by lead buyers. Finally, Lund-Thomsen and Lindgreen (2014) consider specific strategies used by lead firms seeking to address challenges related to sustainable 


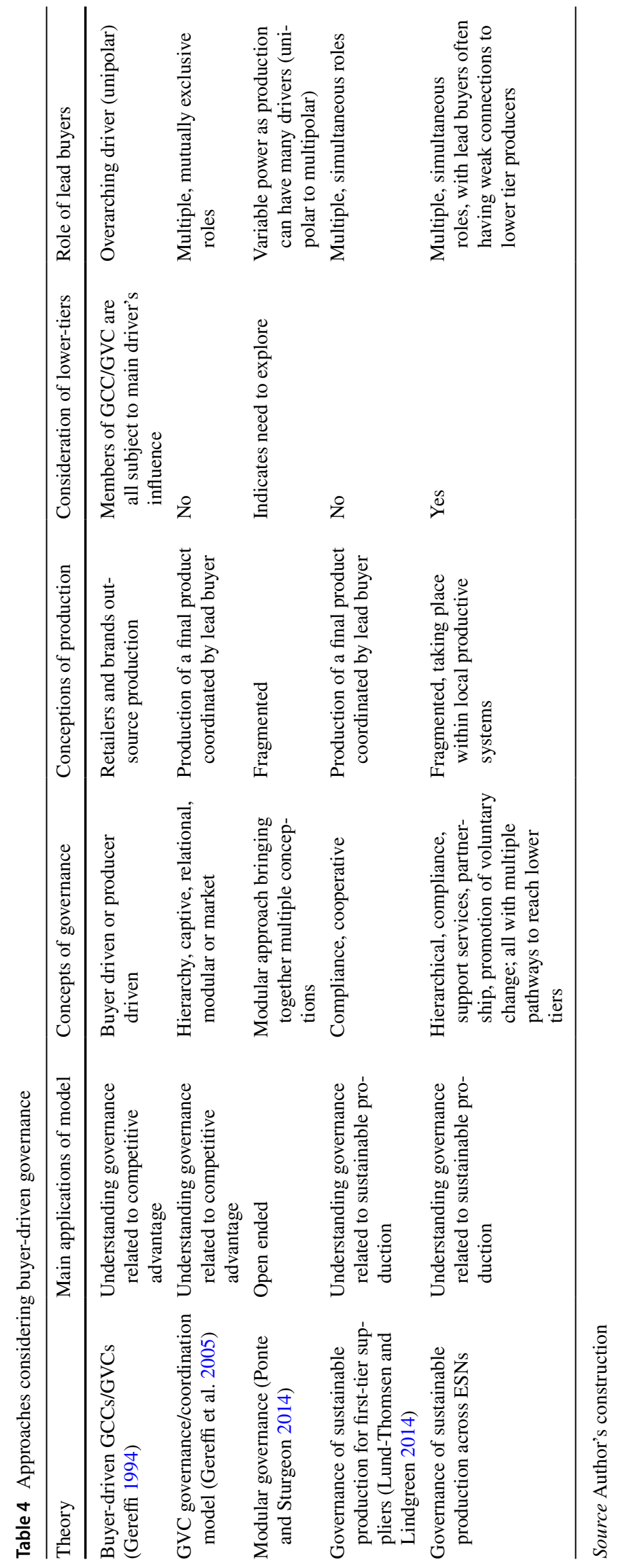


production found in first-tier suppliers. The approaches to buyer-driven governance identified in this study provide a different way to think about buyer-led governance than these key past approaches (see Table 4). This article presents lead firms' role in governance for sustainable production as a multi-faceted process. From this perspective, one lead firm has the potential to play multiple, simultaneous governance roles.

Five model mechanisms are identified as Hierarchical, Compliance, Support Services, Partnership and the Promotion of Voluntary Change. The mechanisms are not mutually exclusive and are often combined within one strategy. The approaches available to lead firms depend on their relationships with producers along with the nature of the sustainability challenge being faced. The mechanisms can involve both vertical and horizontal ties. Each pathway has different benefits. Strengthening or shortening vertical connections can be seen as a way to reduce risk created by outsourcing. Creating horizontal connections can be seen as a way to reach broad groups of producers that are not easily accessible through vertical pathways.

Empirically, this study has found that, while retailers currently do not play a large role in governance for sustainability across this case study, this role is expanding. Working through both vertical and horizontal connections, retailers are connecting to producers in diverse local productive systems by developing cooperative relationships with other governance actors and using a variety of approaches for promoting changes to production practices.

Considering the five mechanisms identified in this case and the two types of pathways discussed can help provide insight for buyer-driven industries beginning to engage in promoting sustainability in their production processes. This study emphasises that there are many ways to address sustainability concerns outside of the dominant compliance approach. It also shows that multiple approaches can be pursued in parallel by individual lead firms facing diverse sustainability challenges in their ESNs.

\section{Limitations}

This study is limited by focusing on one industry in one period of time. Additionally, as the network studied is large and diverse, the empirical material only provides a small glimpse of what is happening across the entire network. However, the practices and processes identified allow for the development of a model that can be applied to future cases in order to be refined.

\section{Future Research}

As sustainability challenges in global production processes present an ongoing problem, more research is needed to better understand the role that lead firms can play in promoting sustainable practices. Subsequent studies could benefit from considering additional sectors and country contexts. Further research could involve an in-depth exploration of how firms choose approaches, the prevalence of their use and their effectiveness. An area of particular concern is questioning the types of impact that international firms can have on local communities (Kolk and Lenfent 2018).

Another interesting area to consider is how lead firms progress in developing new approaches. Kim and Davis (2016) note that initial engagement in CSR can shape future behaviour. They highlight that previous studies have found that firms that adopt CSR practices can continue developing these practices even if they have initially introduced aspects of CSR solely for symbolic purposes (Kelly and Dobbin 1998) and that firms publically regarded as having high levels of CSR are treated harshly if their reputations are damaged (King and McDonnell 2015). Another issue is whether new approaches adopted by some lead firms lead to broader industry-wide changes due to mimetic processes (Zhu and Sarkis 2007). A longitudinal study on firms' strategies for CSR in supplier networks could provide more insight into these dynamics.

\section{Compliance with Ethical Standards}

Conflict of interest Rachel Alexander declares that she has no conflict of interest.

Open Access This article is distributed under the terms of the Creative Commons Attribution 4.0 International License (http://creativeco mmons.org/licenses/by/4.0/), which permits unrestricted use, distribution, and reproduction in any medium, provided you give appropriate credit to the original author(s) and the source, provide a link to the Creative Commons license, and indicate if changes were made.

\section{References}

AEPC. (2009). Indian apparel clusters: An assessment. Delhi, India: Apparel Export Promotion Council.

Alexander, R. (2018). Sustainability in global production networksIntroducing the notion of extended supplier networks. Competition and Change, 22(3), 255-273.

Amengual, M. (2010). Complementary labor regulation: The uncoordinated combination of state and private regulators in the Dominican Republic. World Development, 38(3), 405-414.

Bair, J. (2008). Analysing global economic organization: Embedded networks and global chains compared. Economy and Society, 37(3), 339-364.

Bair, J., \& Werner, M. (2015). Global production and uneven development: When bringing labour in isn't enough. In K. Newsome, P. 
Taylor, J. Bair, \& A. Rainnie (Eds.), Putting labour in its place: Labour process analysis and global value chains (pp. 119-134). London: Palgrave.

Baker, G., Gibbons, R., \& Murphy, K. J. (2002). Relational contracts and the theory of the firm. The Quarterly Journal of Economics, $117(1), 39-84$.

Barrie, L. (2014). Interview: String traceability tool goes back to basics. Just Style.

Barrientos, S., \& Smith, S. (2007). Do workers benefit from ethical trade? Assessing codes of labour practice in global production systems. Third World Quarterly, 28(4), 713-729.

Bartley, T. (2003). Certifying forests and factories: States, social movements, and the rise of private regulation in the apparel and forest products fields. Politics and Society, 31(3), 433-464.

Bartley, T. (2010). Transnational private regulation in practice: The limits of forest and labor standards certification in Indonesia. Business and Politics, 12(3), 1-34.

Borgatti, S. P., \& Li, X. (2009). On social network analysis in a supply chain context. Journal of Supply Chain Management, 45(2), 5-22.

Brown, D., \& Knudsen, J. (2015). Domestic institutions and market pressures as drivers of corporate social responsibility: Company initiatives in Denmark and the UK. Political Studies, 63(1), 181-201.

Carter, C. R., \& Easton, P. L. (2011). Sustainable supply chain management: Evolution and future directions. International journal of physical distribution \& logistics management, 41(1), 46-62.

Carter, C. R., \& Rogers, D. S. (2008). A framework of sustainable supply chain management: Moving toward new theory. International journal of physical distribution \& logistics management, 38(5), 360-387.

Choi, T. Y., Dooley, K. J., \& Rungtusanatham, M. (2001). Supply networks and complex adaptive systems: Control versus emergence. Journal of Operations Management, 19(3), 351-366.

Coase, R. H. (1937). The nature of the firm. Economica, 4(16), 386-405.

Coe, N. M., Dicken, P., \& Hess, M. (2008). Global production networks: Realizing the potential. Journal of Economic Geography, 8(3), 271-295.

Coe, N. M., \& Yeung, H. W. C. (2015). Global production networks: Theorizing economic development in an interconnected world. Oxford: Oxford University Press.

Darby, M. R., \& Karni, E. (1973). Free competition and the optimal amount of fraud. Journal of Law and Economics, 16(1), 67-88.

Davis, G. F., von Neumann Whitman, M., \& Zald, M. N. (2013). Political agency and the responsibility paradox. In B. Maiguashc \& R. Marchetti (Eds.), Contemporary political agency: Theory and practice (pp. 92-117). Abingdon: Routledge.

De Marchi, V., Di Maria, E., \& Ponte, S. (2013). The greening of global value chains: Insights from the furniture industry. Competition and Change, 17(4), 299-318

De Marchi, V., \& Grandinetti, R. (2013). Knowledge strategies for environmental innovations: The case of Italian manufacturing firms. Journal of Knowledge Management, 17(4), 569-582.

De Neve, G. (2009). Power, inequality and corporate social responsibility: The politics of ethical compliance in the south Indian garment industry. Economic and Political Weekly, XLIV(22), 63-72.

Dyer, J. H., \& Singh, H. (1998). The relational view: Cooperative strategy and sources of interorganizational competitive advantage. Academy of Management Review, 23(4), 660-679.

Feddersen, T. J., \& Gilligan, T. W. (2001). Saints and markets: Activists and the supply of credence goods. Journal of Economics and Management Strategy, 10(1), 149-171.

Gereffi, G. (1994). The organization of buyer-driven global commodity chains: How US retailers shape overseas production networks. In G. Gereffi \& M. Korzeniewicz (Eds.), Commodity chains and global capitalism (pp. 95-122). Westport, CT: Praeger Publishers.
Gereffi, G., Humphrey, J., \& Sturgeon, T. (2005). The governance of global value chains. Review of International Political Economy, 12(1), 78-104.

Gereffi, G., \& Lee, J. (2012). Why the world suddenly cares about global supply chains. Journal of Supply Chain Management, 48(3), 24-32.

Gereffi, G., \& Lee, J. (2016). Economic and social upgrading in global value chains and industrial clusters: Why governance matters. Journal of Business Ethics, 133(1), 25-38.

Gereffi, G., \& Mayer, F. (2006). Globalization and the demand for governance. In G. Gereffi (Ed.), The new offshoring of jobs and global development (pp. 39-58). Geneva: ILO.

Gibbon, P., Bair, J., \& Ponte, S. (2008). Governing global value chains: An introduction. Economy and Society, 37(3), 315-338.

Grimm, J. H., Hofstetter, J. S., \& Sarkis, J. (2014). Critical factors for sub-supplier management: A sustainable food supply chains perspective. International Journal of Production Economics, 152, 159-173.

Guinée, J. B., et al. (2011). Life cycle assessment: Past, present, and future. Environmental Science and Technology, 45(1), 90-96.

Henderson, J., et al. (2002). Global production networks and the analysis of economic development. Review of International Political Economy, 9(3), 436-464.

Hess, M. (2004). 'Spatial' relationships? Towards a reconceptualization of embeddedness. Progress in Human Geography, 28(2), $165-186$

Hofstetter, J. S. (2018). Extending management upstream in supply chains beyond direct suppliers. IEEE Engineering Management Review, 46(1), 106-116.

Humphrey, J., \& Schmitz, H. (2000). Governance and upgrading: Linking industrial cluster and global value chain research (Vol. 120). Brighton: Institute of Development Studies.

Humphrey, J., \& Schmitz, H. (2001). Governance in global value chains. IDS Bulletin, 32(3), 19-29.

Jooste, S. F., \& Scott, W. R. (2011). Organizations enabling public private partnerships: An organization field approach. In W. R. Scott, R. E. Levitt, \& R. J. Orr (Eds.), Global projects: Institutional and political challenges (pp. 377-402). Cambridge: Cambridge University Press.

Kelly, E., \& Dobbin, F. (1998). How affirmative action became diversity management: Employer response to antidiscrimination law, 1961 to 1996. American Behavioral Scientist, 41(7), 960-984.

Kim, Y. H., \& Davis, G. F. (2016). Challenges for global supply chain sustainability: Evidence from conflict minerals reports. Academy of Management Journal, 59(6), 1896-1916.

King, B. G., \& McDonnell, M.-H. (2015). Good firms, good targets: The relationship between corporate social responsibility, reputation, and activist targeting. In K. Tsutsui \& A. Lim (Eds.), Corporate social responsibility in a globalizing world (pp. 430-454). New York: Cambridge University Press.

Klassen, R. D., \& Vereecke, A. (2012). Social issues in supply chains: Capabilities link responsibility, risk (opportunity), and performance. International Journal of Production Economics, 140(1), $103-115$.

Kolk, A., \& Lenfant, F. (2018). Responsible business under adverse conditions: Dilemmas regarding company contributions to local development. Business Strategy \& Development, 1(1), 8-16.

Kühnen, M., \& Hahn, R. (2018). Systemic social performance measurement: Systematic literature review and explanations on the academic status quo from a product life-cycle perspective. Journal of Cleaner Production, 205, 690-705.

Levy, D. L. (2008). Political contestation in global production networks. Academy of Management Review, 33(4), 943-963.

Locke, R. M. (2013). The promise and limits of private power: Promoting labor standards in a global economy. New York: Cambridge University Press. 
Lund-Thomsen, P., \& Lindgreen, A. (2014). Corporate social responsibility in global value chains: Where are we now and where are we going? Journal of Business Ethics, 123(1), 11-22.

Lund-Thomsen, P., \& Nadvi, K. (2010). Clusters, chains and compliance: Corporate social responsibility and governance in football manufacturing in South Asia. Journal of Business Ethics, 93, 201-222.

Mayer, F., \& Gereffi, G. (2010). Regulation and economic globalization: Prospects and limits of private governance. Business and Politics, 12(3), 1-25.

Mena, C., Humphries, A., \& Choi, T. Y. (2013). Toward a theory of multi-tier supply chain management. Journal of Supply Chain Management, 49(2), 58-77.

Mezzadri, A. (2014). Backshoring, local sweatshop regimes and CSR in India. Competition and Change, 18(4), 327-344.

Mintel. (2013). Clothing Retailers UK October 2013. London: Mintel.

Nadvi, K., \& Raj-Reichert, G. (2015). Governing health and safety at lower-tiers of the computer industry global value chain. Regulation and Governance, 9(3), 243-258.

Ng, R., \& Mirchandani, K. (2008). Linking global trends and local lives: Mapping the methodological dilemmas. In K. Gallagher (Ed.), The methodological dilemma: Creative, critical and collaborative approaches to qualitative research (pp. 34-45). Abingdon: Routledge.

O'Rourke, D. (2003). Outsourcing regulation: Non- governmental systems of labor standards and monitoring. Policy Studies Journal, 31(31), 1-29.

Parlett, M., \& Hamilton, D. (1972). Evaluation as illumination: A new approach to the study of innovatory programs. Edinburgh: Centre for Research in the Educational Sciences, University of Edinburgh.

Pietrobelli, C., \& Saliola, F. (2008). Power relationships along the value chain: Multinational firms, global buyers and performance of local suppliers. Cambridge Journal of Economics, 32(6), 947-962.

Ponte, S., \& Sturgeon, T. (2014). Explaining governance in global value chains: A modular theory-building effort. Review of International Political Economy, 21(1), 195-223.

Sarkis, J., Zhu, Q., \& Lai, K. H. (2011). An organizational theoretic review of green supply chain management literature. International Journal of Production Economics, 130(1), 1-15.

Sauer, P. C., \& Seuring, S. (2018). A three-dimensional framework for multi-tier sustainable supply chain management. Supply Chain Management: An International Journal, 23(6), 560-572.

Schrempf-Stirling, J., Palazzo, G., \& Phillips, R. A. (2013). Ever expanding responsibilities: Upstream and downstream corporate social responsibility. In A. Lindgreen, F. Maon, J. Vanhamme, \& S. Sen (Eds.), Sustainable value chain management. Farnham: Gower Publishing Ltd.

Schüßler, E., et al. (2018). Changes in the Governance of Garment Global Production Networks: Lead Firm, Supplier and Institutional Responses to the Rana Plaza Disaster, Garment Supply Chain Governance Interim Report November 2018. Berlin: Garment Supply Chain Governance Project.
Scott, W. R. (2014). Institutions and organizations: Ideas, interests and identities (4th ed.). Thousand Oaks, CA: SAGE Publications.

Sinkovics, R. R., \& Alfoldi, E. A. (2012). Progressive focusing and trustworthiness in qualitative research. Management International Review, 52(6), 817-845.

Sinkovics, R. R., Penz, E., \& Ghauri, P. N. (2008). Enhancing the trustworthiness of qualitative research in international business. Management International Review, 48(6), 689-714.

Smith, D. (2005). Institutional ethnography: A sociology for people. Lanham, MD: AltaMira Press.

Soundararajan, V., \& Brown, J. A. (2016). Voluntary governance mechanisms in global supply chains: Beyond CSR to a stakeholder utility perspective. Journal of Business Ethics, 134(1), 83-102.

Stake, R. E. (2010). Qualitative research: Studying how things work. New York: The Guildford Press.

Sumner, J. (2005). Value wars in the new periphery: Sustainability, rural communities and agriculture. Agriculture and Human Values, 22, 303-312.

Tachizawa, E. M., \& Wong, C. Y. (2014). Towards a theory of multitier sustainable supply chains: A systematic literature review. Supply Chain Management: An International Journal, 19(5/6), 643-663.

Theuws, M., \& Overeem, P. (2014). Flawed fabrics: The abuse of girls and women workers in the south Indian textile industry, SOMO. The Netherlands: Amsterdam \& Utrecht.

UN Statistics Division. (2015). UN Comtrade. New York. Retrieved from http://comtrade.un.org/db.

Welford, R., \& Frost, S. (2006). Corporate social responsibility in Asian supply chains. Corporate Social Responsibility and Environmental Management, 13(3), 166-176.

Wilkinson, F. (2003). Productive systems and the structuring role of economic and social theories. In B. Burchell, S. Deakin, J. Michie, \& J. Rubery (Eds.), Systems of production: Markets organisations and performance (pp. 10-39). London: Routledge.

Williamson, O. E. (1979). Transaction-cost economics: The governance of contractual relations. The Journal of Law \& Economics, 22(2), 233-261.

Williamson, O. E. (1981). The economics of organization: The transaction cost approach. American Journal of Sociology, 87(3), 548-577.

Yan, T., Choi, T. Y., Kim, Y., \& Yang, Y. (2015). A theory of the nexus supplier: A critical supplier from a network perspective. Journal of Supply Chain Management, 51(1), 52-66.

Zhu, Q., \& Sarkis, J. (2007). The moderating effects of institutional pressures on emergent green supply chain practices and performance. International Journal of Production Research, 45(18-19), 4333-4355.

Publisher's Note Springer Nature remains neutral with regard to jurisdictional claims in published maps and institutional affiliations. 